\title{
Determinants of Six-Month Appointment Spacing Model Utilization Among ART Clients in the Public Health Facilities of Jimma Town, Southwest Ethiopia: Case-Control Study
}

This article was published in the following Dove Press journal: HIVIAIDS - Research and Palliative Care

\author{
Goshu Ragea (iD) \\ Fessahaye Alemseged (iD) $2, \dagger$ \\ Mamo Nigatu (iD ${ }^{2}$ \\ Diriba Dereje (D) $^{3}$ \\ 'Department of HIV/AIDS Prevention \\ and Control, CDC Oromia, Jimma, \\ Ethiopia; ${ }^{2}$ Department of Epidemiology, \\ Jimma University, Jimma, Ethiopia; \\ ${ }^{3}$ Department of Biomedical Science, \\ Jimma University, Jimma, Ethiopia \\ ${ }^{\dagger}$ Dr Fessahaye Alemseged passed away on \\ August 7, 2020
}

Background: Ethiopia is currently implementing an Appointment Spacing Model (ASM) for ART. A study conducted in 6 hospitals that piloted ASM showed that 51\% of eligible clients declined ASM. Studies conducted on ASM have focused on its benefits, not factors determining its utilization. This study aimed to identify determinants of ASM non-utilization. Objective: To identify determinants of ASM non-utilization among stable ART clients.

Methods: An unmatched case-control study was conducted among 194 cases and 194 controls: consecutively selected stable clients on anti-retroviral therapy (ART) at four public health facilities in Jimma town. Data were collected through face-to-face interviews and observation techniques using semi-structured questionnaire and observation checklist. EpiData version 3.1 and SPSS version 23 were respectively used for data entry and analysis. Descriptive statistics, logistic regression, adjusted odds ratio and 95\% CI were used to summarize descriptive data, identify determinants of ASM non-utilization, measure the strength of statistical association, and declare the statistical significance respectively.

Results: With $100 \%$ response rate, predictors of ASM non-utilization were residing in urban areas $(\mathrm{AOR}=2.61,95 \% \mathrm{CI}$ : 1.10-6.18), fear regarding drug safety $(\mathrm{AOR}=3.19,95 \% \mathrm{CI}$ : $1.56-6.54)$, duration of ART ( $<5$ years) $(\mathrm{AOR}=2.45,95 \% \mathrm{CI}: 1.17-5.16)$, need for frequent checkups (AOR=2.70, 95\% CI: 1.29-5.61), poor understanding of ASM (AOR=3.15, 95\% CI: 1.54-6.43), high perceived difficulties of engagement in ASM (AOR $=10.13,95 \% \mathrm{CI}$ : 4.31-23.84), perceived presence of high opportunistic cost ( $\mathrm{AOR}=3.34,95 \% \mathrm{CI}: 1.64-6.83$ ), low self-efficacy (AOR=7.44, 95\% CI: 3.16-17.46), recent history of opportunistic infection $(\mathrm{AOR}=3.34,95 \% \mathrm{CI}: 1.64-6.83)$, absence of competing family activities (AOR=4.39, 95\% CI: 2.05-9.44) and stigma (AOR=2.85, 95\% CI: 1.39-5.81).

Conclusion: The majority of factors affecting ASM non-utilization were behavioral and community related, which can be addressed by health education both at client and community level and additionally, by training service providers to address factors connected with the provision of service. Qualitative study and impact assessment on client retention are recommended for further research.

Keywords: ASM, HIV/AIDS, public health facility, Jimma

\section{Introduction}

Globally, in 2018, 37.9 million people were living with Human Immunodeficiency Virus (HIV), 1.2 million were newly infected and 21.7 million people were on antiretroviral therapy (ART). ${ }^{1,2}$ About 25.6 million people were living with HIV
Correspondence: Goshu Ragea Email grgoshu20@gmail.com 
(PLWHIV) in Sub-Saharan Africa, making it the most affected region, which accounts for two-thirds of the global total of new HIV infections. ${ }^{3,4}$ In Ethiopia the national adult (15-49 years) HIV prevalence was $0.93 \%$ in 2019 . As per the 2019 Ethiopian Public Health Institute (EPHI) HIV estimates and projections, the estimated number of PLWHIV were 665,723 of which 39,792 are $<15$ years. ${ }^{1}$

Improving access to ART for PLWHIV has been identified as an important strategy to control HIV epidemic and avoid its future cost. ${ }^{5}$ Achievement of the 90-90-90 targets and implementation of "test and treat" needs the development and adoption of innovative, differentiated models for HIV diagnosis and ART delivery to meet the diverse needs of PLWHIV. Differentiated service delivery (DSD) is a clientcentered approach that simplifies and adapts HIV treatment and prevention services along the cascade of care to respond to the preferences and expectations of various groups of PLWHIV. $^{6}$ It serves to reduce extra burden on the health system and also improves PLWHIV's needs. Through this approach, the general population, pregnant women, children, adolescents, and Key Vulnerable Populations (KVPs), living in urban or rural settings can all have models of care developed to fit their needs. DSD models are designed according to three elements: clinical characteristics or needs, subpopulation, and environmental context. ${ }^{7}$

In response to the HIV epidemic, a five-year national HIV and AIDS strategic plan was developed by Ethiopia (20152020) based on the UNAIDS investment framework strategy and Federal HIV/AIDs prevention and control office (FHAPCO) in 2014. With the release of the WHO 2016 guidelines, the era of "treat all", putting all HIV-positive individuals on ART is upon the health sector. The expanded eligibility for treatment puts strain on health systems in challenging environments that lack human and financial resources. ${ }^{8,9}$

Ethiopia has adopted the appointment spacing model (ASM) of service delivery by considering the sociocultural situation, degree of awareness, stigma and discrimination, resource demand and its sustainability. Implementation of ASM improves service quality, results in cost savings, improves health outcomes, accelerates the achievement of the 90-90-90 target by offloading workload from overburdened health facilities, and improves adherence and retention. ${ }^{10}$ As ART cohorts mature, a growing number of people in treatment programs will virally suppress. In this case frequent laboratory and clinical monitoring is not required. Further, by reducing the burden of stable clients visiting health facilities, resources can be reallocated to clients most in need. ${ }^{11}$
To enroll an ART client in ASM, first the health care provider (HCP) screens their client for eligibility. Eligible clients are those who fulfil WHO category 4 (stable individuals who have received ART for at least one year and have no adverse drug reactions that require regular monitoring and have good understanding of lifelong adherence and evidence of treatment success). Eligible clients will be offered and recommended to enroll in ASM. Stable ART clients who accept the offer will be enrolled in ASM, supplied with enough medication, and scheduled to visit the clinic every six months for both clinical visit and medication refill. The Federal ministry of health (FMoH) scaled up ASM in all ART providing sites. Until February 2018, there were 974 sites providing ASM. The number of ART clients screened to be eligible and enrolled in the ASM by December, 2017 were 138,096 and 69,074 respectively, thus only $49 \%$ of eligible clients use ASM. ${ }^{12}$

Findings from different literature show that utilization of ASM is associated with improvement in retention $(97 \%),{ }^{3,6,13}$ decreased lost to follow up (it significantly decreases missed appointments from $24.4 \%$ to $20.3 \%$ ), ${ }^{14}$ reduced cost of service compared to the standard approach and improved adherence to treatment. ${ }^{15,16}$ It also improves median waiting time and providers' satisfaction. ${ }^{17}$

Other findings on ASM non-utilization showed that it is associated with increased death, lost to follow-up (LTFU) and poor retention. ${ }^{18,19}$ Five years after the first ASM eligibility, the cumulative probability of death among HIV patients on ART was 56.3\% (95\% CI: $52.4-$ $60.2 \%$ ) among never enrollees, $13.9 \%$ (95\% CI: $12.5-$ $15.6 \%)$ among late enrollees, and $8.1 \% \quad(95 \%$ CI 7.2-9.0\%) among early enrollees in ASM ("early enrollees" is enrollment within six months, while "late" is after six months of eligibility for ASM). The before and after done in Malawi showed significantly higher rate of LTFU in non-ASM periods as compared with ASM periods (adjusted rate ratio: $1.87,95 \%$ CI $1.68-2.08, \mathrm{p}<0.001$ ). ${ }^{20}$

Despite the fact that active utilization of the ASM benefits both ART clients and service providers, not all eligible clients are utilizing the current ASM being implemented at ART clinics. According to a pilot study conducted in Ethiopia in April 2017 by International Cooperation for AIDs Prevention (ICAP) in collaboration with $\mathrm{FMoH}$ and center for disease control (CDC), the major reasons cited for refusal to participate in the ASM were fear of inadvertent disclosure. This is because, having a large volume of medication causes concerns regarding safety and storage of medication for prolonged periods at home. ${ }^{12}$ 
Even though different studies were done in the different MLIC (middle and low-income countries) to explore the benefits of ASM utilization, to the best knowledge of the investigators, there was no study done to identify determinants of ASM non-utilization. ${ }^{21-32}$ Therefore, this research aimed to assess different factors that hinder stable ART clients at the Jimma town public health facilities from utilizing ASM.

\section{Methods}

\section{Study Area and Period}

Jimma town is a capital town of Jimma zone with 205,163 total population. The town has 28 medium clinics, 7 primary clinics, 3 NGO clinics, 4 diagnostic laboratories, 21 pharmacies, 33 drug stores and 1 primary hospital owned by private sector. There are two public hospitals namely: Jimma medical center (JMC) and Shanan Gibe General hospital (SGGH) and five public health centers: Jimma higher I, Jimma higher II, Mendera Kochi, Bacho Bore and First-Italy health center (data obtained from Jimma town health office, 2019).

In 2019 there were about 4782 PLWHIV (4448 adults and 334 children) who had been on ART medication at the four public health facilities. The Jimma Higher I Health Center had been providing the ART service for 863 clients out of which 467 clients were enrolled in ASM, the Jimma Higher II Health Center had been providing the service for 126 ART clients out of which 8 clients were on ASM, the JUMC ART clinic had been providing the service for 3222 ART clients and the Shanan Gibe General hospital for 500 ART clients. At the SGGH there were 474 adults (151 male and 323 female) receiving ART care and support out of which 46 clients were receiving PMTCT service; 42 clients had high viral load (HVL). Among 298 eligible clients at the SGGH, only 206 (69\%) were enrolled in ASM while $92(31 \%)$ had declined it. The study was conducted from February 1 to 30, 2019 to identify underlying factors of ASM non-utilization among the two public health centers and the two public hospitals mentioned previously (Figure 1).

The FMoH currently recommends routine screening and categorization of ART clients visiting a health facility for clinical follow-up and medication refill. All clients fulfilling the WHO criteria for stable client category 4 will be offered, and those volunteer are registered and scheduled for six-month visits for both clinical evaluation and medication refill.

\section{Study Design}

Unmatched facility-based case-control study was conducted by recruiting both existing and new cases.

\section{Population}

The source population was all the stable clients on medication from the ART clinics at the four public health facilities in Jimma town. The study population was all stable clients visiting the ART clinics at the four public health facilities in Jimma to collect their ART drugs within the study period and who fulfilled the inclusion criteria. Cases were all eligible clients who declined accepting ASM before the commencement of the study and controls were all eligible clients who were enrolled in ASM before the study commenced. All cases and controls who fulfilled the WHO care category four and were greater than 18 years of age were included in the study. All cases and controls who were critically ill and unable to respond to the questionnaire were excluded from the study.

\section{Sample Size Determination}

Sample of stable clients on ART: 388 of which 194 were controls and 194 were cases, determined using Epinfo7 software at $95 \%$ C.I, $80 \%$ power, $(69 \%)$ proportion of female patients on ASM at SGGH, OR of 2.02 and 1:1 ratio of controls to cases. $1 \%$ of the calculated sample size was added to account for non-respondents. In this study, cases and controls had been recruited consecutively. (Data from SGGH 2018).

\section{Sampling Technique/Sampling Procedures}

The calculated numbers of samples were proportionally allocated to each ART-providing public health facility in Jimma town (i.e., JMC, SGGH, Higher I and Higher II Health center). Then, ART providers, after providing the required services, identified stable clients using the screening criteria and informed them to contact data collectors by filling the screening forms and coding as "stable on ASM" or "stable not on ASM".

All clients fulfilling the inclusion criteria for cases and controls as mentioned previously were included and contacted consecutively until it reached the required sample size during the study period. Cases and controls were selected from a register (ART) and by using screening questions. Controls were also selected from a register and by using 


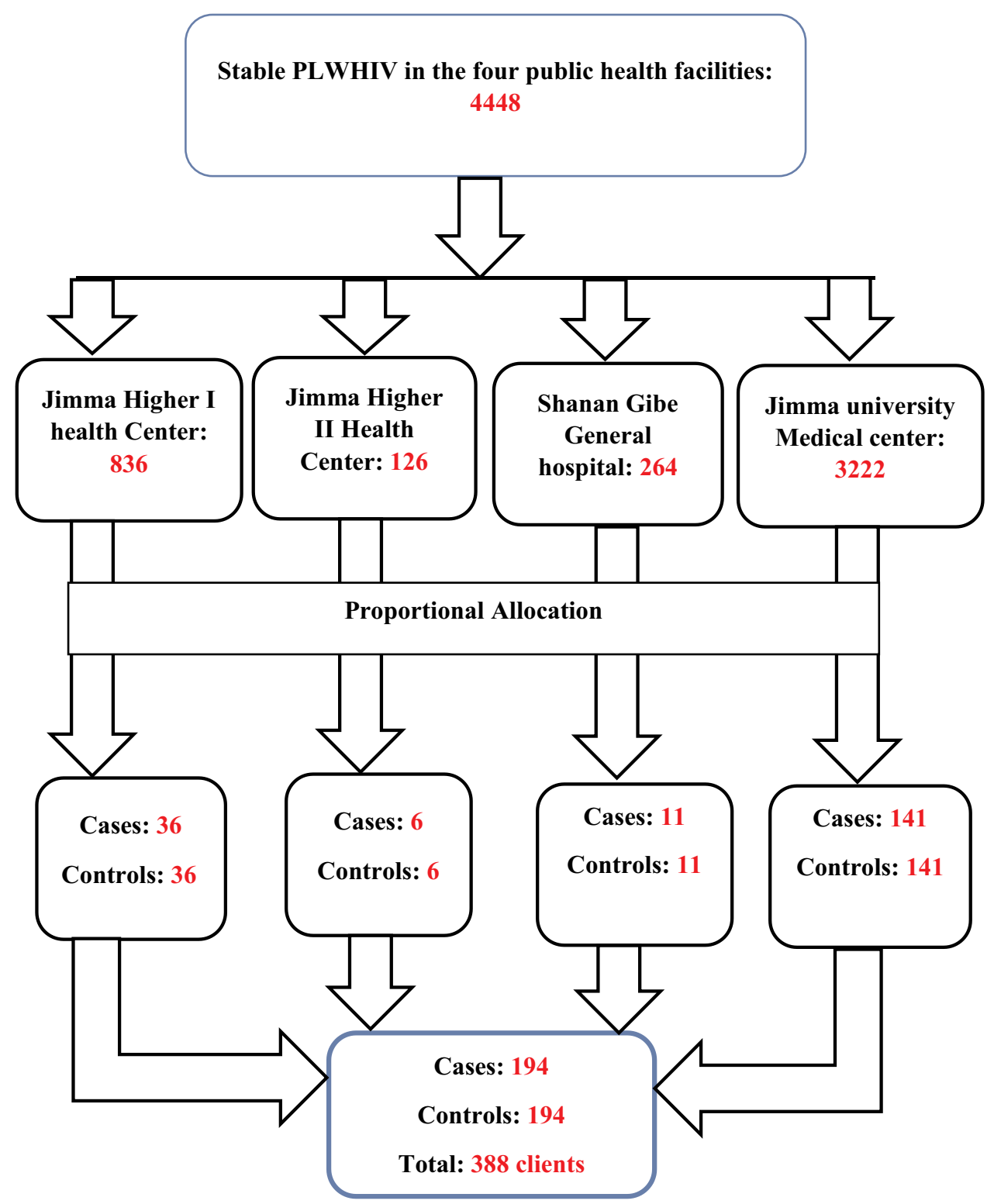

Figure I Proportionate allocation of sample size among the four public health facilities.

screening questions and contacted consecutively for each case identified until cases were fully addressed (Figure 1).

Measurement

Study Variables

Dependent Variable

ASM non-utilization status.

Independent Variables

I - Intrapersonal (Mainly Individual Characteristics).

1. Socio-demographic characteristics
Age, sex, marital status, residence, education, religion, ethnicity, occupation; monthly income.

2. Behavioral (cognitive or psychological processes experienced by the individual)

Intervention experience, knowledge of how ASM works, ever enrolled in ASM, current enrollment status in ASM, reason for non-enrollment currently, patients' feelings toward ASM and purpose of ASM.

3. Connectedness to care

Duration of ART, years lived with HIV, level of ART adherence and history of LTFU.

4. Biological 
Laboratory profile, recent CD4 count and recent viral load status.

5. Care history and comorbidity

History of severe HIV related infection, current health status, mental health screening (depression, mood disorder) and history of comorbidity (chronic disease).

II - Interpersonal (Relationship Variables).

1. Provider-related factors

Client's judgement of provider's competencies, intervention coherence, providers' understanding of components of ASM, how it works, provider recommendation, patient's understanding of components of ASM and how it works, and patient's perceptions of provider.

2. Community related factors

Disclosure status, reason for non-disclosure, social support, family support, presence of stigma, level of stigma, and presence of competing family activities, ethicality, patient belief and culture.

III - Extra-Personal (External Variables That Have Impact on the Individual's Ability to Be on ASM)

1. Health service care coordination

Availability of adequate drugs, convenience of service, food supply, laboratory, waiting times, opportunity cost, loss due to engagement in ASM, service related, economy and time.

2. Environmental

Distance from clinic, housing condition, history of stable relationship with partner, duration of relationship with partner, number of family members living together, unstable housing, paying for travel, and amount to pay for regular visits.

\section{Operational Definitions}

1. a. ASM utilization: appointment spacing model utilized by client when an eligible ART client fulfilling WHO criteria (treatment category IV) accepts provider's offer for attending his/her follow up every six months and enrolled in the schedule for both clinical evaluation and medication refill

1. b. Non-utilizers of ASM: are those ART clients, who fulfil the WHO criteria of stable patient, were offered to be enrolled in ASM by ART providers but refused to be engaged in the program (ASM)

2. Stigma: patient is said to have experienced stigma if he/she reported at least one of the following:
1. Self-blame (internalized stigma)

2. Fear of potential criticism from others (anticipated)

3. Encountered discrimination (experienced)

3. Convenience of service: if yes to all of the following options:

1. ART provider available

2. Laboratory obtained as requested timely

3. Availability of all prescribed medication (onsite and timely)

4. Access to ART provider immediately

4. Affective attitude (patient's feelings toward ASM):

1. Patient's opinion regarding importance of ASM

5. Burden: perceived amount of effort to engage in ASM

1. Cognitive: difficulty to remember appointment date

2. Financial: need of additional

6. Ethicality: ASM fitting in with individual's value system

1. Belief: problem with personal belief (religion)

2. Culture: presence of cultural contradiction

7. Intervention coherence: understanding of ASM and how it works

1. Know care package/medication, laboratory service and visit period

1. Opportunity cost: loss to person if engaged:

1. Healthcare: frequent checkups by HCW

2. Loss of free parallel service

3. support (food, material)

1. Perceived effectiveness: extent to which ASM can achieve its purpose

1. LTFU: solve his/her problem, which may have led to missed appointments

2. Retention: can help them stay in care at that facility for longer

3. Work load: save their time for other competing personal work

4. Service cost: can save transportation fee

5. Time to service: reduce waiting time at each visit

2. Self-efficacy: perceived and objective ability to engage in service

1. Confidence: can attend visit every 6 months without missing appointment

2. Use of reminder: can use mobile/chart reminder to remember appointment date 
3. Use of nearby health facility for other health purposes: have capacity and ability to attend nearby heath facility for other health needs

For the following variables, respondents' answers were measured on five-point Likert scale. After asking both negative and positive questions they were categorized as follows for analysis:

1. Affective attitude.

1. >10: good.

2. $\leq 10$ : poor.

2. Perceived difficulty/amount of effort needed to engage in ASM.

1. >12.5: high.

2. $\leq 12.5$ : low.

3. Ethicality/ASM fitting in with individual's value system.

1. $\leq 5$ : not a problem.

2. $>6$ : problem.

4. Intervention coherence/understanding of ASM and how it works.

1. >12.5: good.

2. $\leq 12.5$ : poor.

5. Opportunity cost/loss to a person if engaged in ASM.

1. $\leq 7.5$ : high.

2. >7.5: low.

6. Perceived effectiveness/extent to which ASM can achieve care purpose.

1. >12.5: more likely to achieve its purpose/good.

2. $\leq 12.5$ : less likely to achieve its purpose/poor.

7. Self-efficacy/perceived and objective ability to engage in ASM.

1. <4.5: high/confident.

2. $\geq 4.5$ : low/less confident.

8. Convenience of service/how getting service is conducive to client.

1. $<10$ : convenient.

2. $\geq 10$ : not convenient.

9. Stigma measure/level of prevailed stigma.

1 . $\geq 10$ : highly prevailing.

2. < 10: less likely.

10. Depression cut-off point.

1. $<10$ depression absent.

2. $\geq 10$ depressed present.
Recent opportunistic infection (OI) - was operationalized as those with OI a year prior to time of data collection.

\section{Data Collection Tool}

A semi-structured questionnaire, which contains intrapersonal, interpersonal and extra personal factors, developed in English language from relevant literature review and later translated to Afaan Oromo and retranslated by third person to English was used. An observation checklist was developed to capture clinical data from clients' medical records.

\section{Data Collection Procedure}

The client's status was identified as stable both as user and non-user of ASM, by ART provider. Data collector contacted all the stable clients coded by the provider and proceeded to interviewclients using semi-structured questionnaire. Data on the intrapersonal, interpersonal and extra personal factors collected through face-to-face interviews and observation techniques were utilized to collect the biological data (Figure 2).

\section{Data Analysis Procedures}

Data were entered using EpiData version 3.1 and exported to Statistical Package for Social Sciences (SPSS) version 23 for statistical analysis. Continuous and categorical variables were regrouped and recoded respectively into categories for easy analysis. Descriptive statistics were used to obtain summary values for cases and controls separately. Multi-collinearity was checked using Variance Inflation Factors (VIF) test to avoid highly correlated variables (VIF $<10$ were included for further analysis). Hosmer and Lemeshow test was used to test model fitness, while Wald test was used to identify the significance of individual predictor variables. Bivariate logistic regression analysis was used to identify candidate variables at $p<0.25$ cut-off point. The dependent variable was ASM non-utilization status, while independent variables included sociodemographic, behavioral, biological, service provider related, community related, health system and environment related factors. Significant variables at bivariate analysis were entered into the multivariable logistic regression using backward stepwise logistic regression. Then independent predictors of ASM non-utilization were identified by multivariate logistic regression. Adjusted odds ratio and 


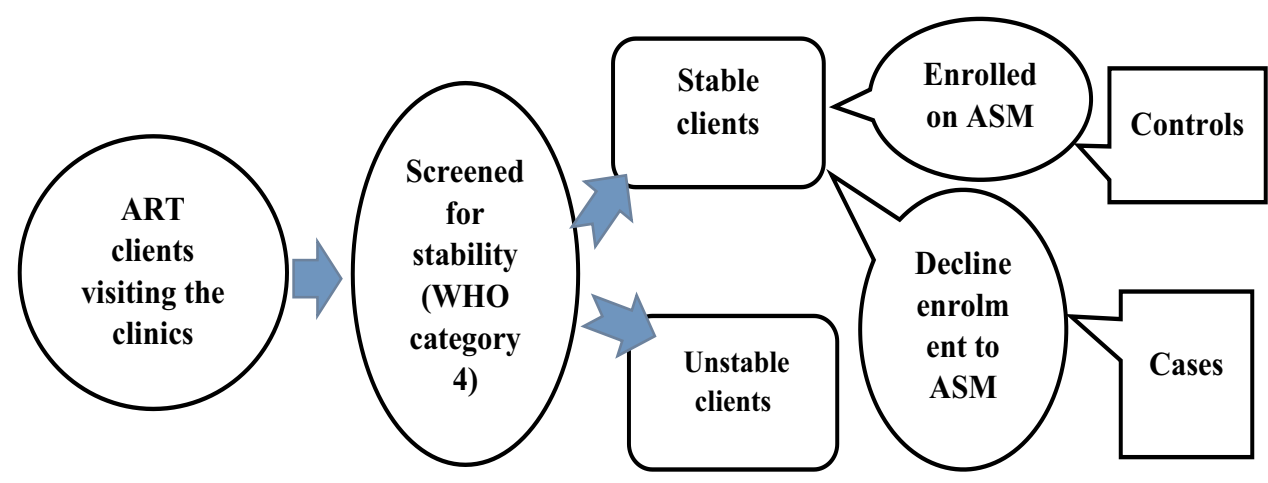

Figure 2 Approaches and steps to identify cases and controls at ART site.

confidence interval $(95 \% \mathrm{CI})$ were used to measure association between predictor variables and model nonutilization, and statistical significance respectively. Statistical significance was declared at $\mathrm{p}<0.05$.

\section{Data Quality Management}

To ensure data quality, the tool was pretested using five percent of the calculated sample size at Limu-Seka Hospital, in adjacent district, and the tool was refined accordingly. Three-day training was given for data collectors and ART providers on data collection instruments. There was daily supervision and checking for data completeness. Data were entered into EpiData version 3.1 after being coded for each study unit and variables using two datasets, and checked for outliers, missing data and managed accordingly. Multivariable logistic regression was employed to ascertain independent association, thereby controlling possible confounder.

\section{Ethical Consideration}

Approval to conduct the research was granted by Jimma university research ethical committee. A letter of permission to undertake data collection was separately written for each of the four public health facilities' management. Management committee from each facility informed their respective ART providers by formal letter. Patient confidentiality and autonomy were maintained by obtaining informed consent prior to any attempt to gain information from each individual client. Client fulfilling the inclusion criteria, after they visited ART providers and completed their routine services, were oriented and consented prior to data collection. No human and/or animal tissue was used in this research. Finally we confirm that the study was conducted as per the declaration of Helsinki.

\section{Results}

\section{Socio-Demographic Characteristics}

A total of 388 respondents, 194 cases and 194 controls, participated in the study making the response rate $100 \%$. Regarding the sex of respondents, 70 (36.1\%) cases and 84 $(43.3 \%)$ controls were male. Majority of respondents, 132 $(68.0 \%)$ cases and $145(74.7 \%)$ controls were $>30$ years of age respectively. Majority of cases, $161(83.0 \%)$ and controls, 138 (71.1\%), were living in urban areas respectively. Regarding their educational status, 47 (24.2\%) cases and $28(14.4 \%)$ controls were not able to read and write. Majority of respondents, 313 (80.7\%), were able to read and write. Regarding respondents who had completed primary education, $55(28.35 \%)$ were cases and 70 (36.08\%) were controls. Regarding the average monthly income: majority, 82 (42.3\%) cases' monthly income was more than1000EB respectively; while, 121 (62.4\%)controls' monthly income was $>1000 \mathrm{~EB}$ respectively (Table 1).

\section{Independent Predictors of Appointment Spacing Model Non-Utilization}

Accordingly, residence (urban), fear regarding drug safety, short ( $<5$ years) duration of ART, need for frequent checkups, high perceived difficulty associated with engagement in the model, poor understanding of the model, selfefficacy, presence of recent opportunistic infection, presence of high opportunistic cost, absence of competing family activities and presence of stigma were independent predictors of ASM non-utilization.

Clients residing in urban areas were about two and a half times more likely to be non-utilizers of the model compared to those who were residing in rural areas $(\mathrm{AOR}=2.61,95 \%$ C.I:1.10-6.18). Patients who had fears regarding drug safety 
Table I Socio-Demographic Characteristics of HIV patients on ART at Jimma University Medical Center, Shanan Gibe General Hospital, Jimma Higher I Health Center and Jimma Higher II Health Center ART Clinics, 2019

\begin{tabular}{|c|c|c|c|c|c|}
\hline \multirow[t]{2}{*}{ Variables } & \multirow[t]{2}{*}{ Category } & \multirow{2}{*}{$\begin{array}{l}\text { Case } \\
\mathrm{N}=194(\%)\end{array}$} & \multirow{2}{*}{$\begin{array}{l}\text { Control } \\
\mathrm{N}=194(\%)\end{array}$} & \multirow[t]{2}{*}{ COR (95\%C.I) } & \multirow[t]{2}{*}{ P-value } \\
\hline & & & & & \\
\hline \multirow[t]{2}{*}{ Sex } & Male & $70(36.1 \%)$ & $84(43.3 \%)$ & I & \\
\hline & Female & $124(63.9 \%)$ & $110(56.7 \%)$ & $1.35(0.89-2.03)$ & $0.147^{*}$ \\
\hline \multirow[t]{2}{*}{ Age } & $(15-30)$ & $62(32.0 \%)$ & $49(25.3 \%)$ & $1.39(0.89-2.16)$ & $0.145^{*}$ \\
\hline & $\geq 30$ & $132(68.0 \%)$ & $145(74.7 \%)$ & 1 & \\
\hline \multirow[t]{2}{*}{ Residence } & Urban & $161(83.0 \%)$ & $138(7 \mid .1 \%)$ & $1.98(1.22-3.22)$ & $0.006 *$ \\
\hline & Rural & $33(17.0 \%)$ & $56(28.9 \%)$ & & \\
\hline \multirow[t]{4}{*}{ Marital status } & Single & $26(13.4 \%)$ & $19(9.8 \%)$ & $1.00(0.46-2.17)$ & 0.983 \\
\hline & Married & $7 I(36.6 \%)$ & $117(60.3 \%)$ & & \\
\hline & Divorced & $59(30.4 \%)$ & $30(15.5 \%)$ & $0.45(0.25-0.79)^{*}$ & 0.006 \\
\hline & Widowed & $38(19.6 \%)$ & $28(\mid 4.4 \%)$ & I.14(0.75-2.79) & 0.268 \\
\hline \multirow[t]{2}{*}{ Educational status } & Can read and write & $\mid 47(75.8 \% \mid)$ & $166(85.6 \%)$ & 1 & \\
\hline & Cannot read and write & $47(24.2 \%)$ & $28(\mid 4.4 \%)$ & $1.89(1.13-3.18)^{*}$ & $0.016^{*}$ \\
\hline \multirow[t]{4}{*}{ Formal Education level } & Primary school & $70(36.08 \%)$ & $55(28.4 \%)$ & 1 & $0.158^{*}$ \\
\hline & Secondary school & $43(22.16 \%)$ & $59(30.4 \%)$ & $0.57(0.34-0.97)^{*}$ & $0.039 *$ \\
\hline & College/university & $19(9.8 \%)$ & $49(25.3 \%)$ & $0.0 .5 \mathrm{I}(0.290 .89)^{*}$ & $0.019 *$ \\
\hline & Not applicable & $10(5.2 \%)$ & $3(1.5 \%)$ & $2.61(0.68-9.97)$ & $0.16^{*}$ \\
\hline \multirow[t]{6}{*}{ Ethnicity } & Oromo & $90(46.4 \%)$ & $90(46.4 \%)$ & I & \\
\hline & Amhara & $66(34.0 \%)$ & $66(34.0 \%)$ & $0.80(0.5 I-1.28)$ & 0.355 \\
\hline & Dawro & $19(9.8 \%)$ & II (5.7\%) & $1.73(0.78-3.84)^{*}$ & $0.179 *$ \\
\hline & Yem & $8(4.1 \%)$ & $4(2.1 \%)$ & $2.00(0.58-6.88)^{*}$ & 0.271 \\
\hline & Kefa & $23(11.8 \%)$ & $12(6.2 \%)$ & $1.92(0.89-4.01)$ & $0.092^{*}$ \\
\hline & Other & $\mathrm{I}(0.5 \%)$ & II (5.7\%) & $0.09(0.11-0.72)$ & $0.023^{*}$ \\
\hline \multirow[t]{6}{*}{ Occupation } & Government employee & $28(\mid 4.4 \%)$ & $52(26.8 \%)$ & $0.63(0.35-1.11)$ & $0.110^{*}$ \\
\hline & Self=employed & $61(31.4 \%)$ & $71(36.6 \%)$ & & 0.397 \\
\hline & Daily laborers & $57(21.4 \%)$ & $22(11.3 \%)$ & $3.02(1.66-5.49)$ & $0.000 *$ \\
\hline & Housewife & $27(13.9 \%)$ & $20(10.3 \%)$ & $1.57(0.80-3.10)$ & $0.187^{*}$ \\
\hline & Farmer or student & $15((7.7 \%)$ & $18(9.3 \%)$ & $0.94(0.45-2.08)$ & 0.970 \\
\hline & Unemployed & $6(3.1 \%)$ & II (5.7\%) & $0.64(0.22-1.82)$ & 0.397 \\
\hline \multirow[t]{3}{*}{ Monthly income } & $\leq 500 \mathrm{~EB}(500-1000) \mathrm{EB}$ & $48(24.7 \%)$ & $37(19.1 \%)$ & $0.73(0.40-1.32)$ & 0.297 \\
\hline & & $64(32.9 \%)$ & $36(18.5 \%)$ & & \\
\hline & $\geq 1000 \mathrm{~EB}$ & $82(42.3 \%)$ & $121(62.4 \%)$ & $0.38(0.23-0.63)$ & $0.013^{*}$ \\
\hline
\end{tabular}

Note: Variables with * are significant and candidates for multivariable analysis except formal education level, age, sex, occupation and ethnicity.

were nearly four times more likely to be non- utilizers of the model as compared to people who had no fear regarding drug safety (AOR $=3.83,95 \% \mathrm{CI}: 1.78-8.19)$. HIV patients who were on ART for less than or equal to 5 years were nearly three times more likely to be non-utilizers of ASM model, as compared to people who had been on ART for more than 5 years (AOR $=2.82,95 \%$ CI:1.28-6.18). Clients who need frequent checkups were about three times more likely to be non-utilizers of the model than their counterparts (AOR=3.12, 95\% CI:1.461-6.66). Clients who had poor understanding (intervention coherence) of the model were about four times more likely to be non-utilizers of the model than those with good understanding $(\mathrm{AOR}=4.24,95 \% \mathrm{CI}$ : 2.05-8.77) (Table 2).

HIV patients who had high perceived difficulties of engagement in the model were about twelve times more likely to be non-utilizers of the model as compared to clients who had low perceived difficulties $(\mathrm{AOR}=12.09$, 95\% CI: 4.97-29.38). HIV patients who had recent history of opportunistic infection were nearly three times more 
likely to be non-utilizers of the model as compared to clients who had no history of recent opportunistic infection (AOR $=2.98,95 \%$ CI: 1.11-7.97). Those clients who had competing family activities were about four three times more likely to be non-utilizers of the model as compared to people who had no competing family activities (AOR $=3.37,95 \%$ CI: 1.534-7.41). Clients with perceived high opportunity cost associated with being in the model were about three times more likely to be non-utilizers of the model as compared to those with low cost $(\mathrm{AOR}=3.34$, 95C.I: 1.64-6.83) (Table 2).

Clients with low self-efficacy were about eight times more likely to be non-utilizers of the model compared to those who had shown high self-efficacy $(\mathrm{AOR}=8.07,95 \%$ CI:3.25-20.02). Clients who reported any form of stigma were about three times more likely to be non-utilizers of the model than those who reported no stigma $(\mathrm{AOR}=3.02$, 95\% CI:1.42-6.38) (Table 2).

\section{Discussion}

The current study was aimed at identifying factors associated with ASM non-utilization among stable clients on ART at public health facility in Jimma town (Figures 1 and 2). Clients residing in urban area were two and a half times more likely to be non-utilizers of the model compared to rural residents. This finding has to do with the fact that rural residents are more likely to live far from the facility which requires either walking long distances or paying more for transport services.

Patients who had fears regarding drug safety were nearly four times more likely to be non-utilizers of the model as compared to people who had no fear regarding drug safety. This is similar to the study conducted in six public hospitals in Addis Ababa which showed that among the $51 \%$ eligible clients who declined ASM utilization the major reason was concerns regarding safety and storage of medication for prolonged periods at home. ${ }^{11} \mathrm{HIV}$ patients who were on ART for less than or equal to 5 years were

Table 2 Independent Predictors of ASM Non-Utilization Among HIV patients on ART at JMC, SGGH, Jimma Higher I Health Center and Jimma Higher II Health Center ART Clinics, 2019

\begin{tabular}{|c|c|c|c|c|c|c|}
\hline Variables & Category & $\begin{array}{l}\text { Case } N=194 \\
(\%)\end{array}$ & $\begin{array}{l}\text { Control } N=194 \\
\text { (\%) }\end{array}$ & COR (95\%C.I) & AOR (95\%C.I) & p value \\
\hline Place of residence & $\begin{array}{l}\text { Urban } \\
\text { Rural }\end{array}$ & $\begin{array}{l}161(83.0 \%) \\
33(17.0 \%)\end{array}$ & $\begin{array}{l}138(71.1 \%) \\
56(28.9 \%)\end{array}$ & $\begin{array}{l}1.98(1.22-3.22) \\
1\end{array}$ & $\begin{array}{l}2.61(1.10-6.18) \\
1\end{array}$ & 0.029 \\
\hline Client duration on ART & $\begin{array}{l}\leq 5 \text { years } \\
>5 \text { years }\end{array}$ & $\begin{array}{l}89(45.9 \%) \\
105(54.1 \%)\end{array}$ & $\begin{array}{l}5 I(26.3 \%) \\
143(73.7 \%)\end{array}$ & $\begin{array}{l}2.37(1.55-3.64) \\
\text { । }\end{array}$ & $\begin{array}{l}2.45((1.17-5.16) \\
1\end{array}$ & 0.018 \\
\hline Need of frequent check ups & $\begin{array}{l}\text { Yes } \\
\text { No }\end{array}$ & $\begin{array}{l}114(58.8 \%) \\
80(41.2 \%)\end{array}$ & $\begin{array}{l}42(21.6 \%) \\
152(78.4 \%)\end{array}$ & $\begin{array}{l}5.15(3.30-8.05) \\
\text { I }\end{array}$ & $\begin{array}{l}2.70(I .29-5.6 I) \\
1\end{array}$ & 0.008 \\
\hline Fear regarding drug safety & $\begin{array}{l}\text { Yes } \\
\text { No }\end{array}$ & $\begin{array}{l}104(53.6 \%) \\
90(46.4 \%)\end{array}$ & $\begin{array}{l}4 \mathrm{I}(21.1 \%) \\
153(78.9 \%)\end{array}$ & $\begin{array}{l}4.31(2.76-6.73) \\
\text { I }\end{array}$ & $\begin{array}{l}3.19(1.56-6.54) \\
1\end{array}$ & 0.002 \\
\hline $\begin{array}{l}\text { History of recent opportunistic } \\
\text { infection }\end{array}$ & $\begin{array}{l}\text { Yes } \\
\text { No }\end{array}$ & $\begin{array}{l}46(23.7 \%) \\
148(90.2 \%)\end{array}$ & $\begin{array}{l}19(9.8 \%) \\
175(90.2 \%)\end{array}$ & $\begin{array}{l}2.86(1.61-5.10) \\
I\end{array}$ & $\begin{array}{l}3.81(1.42-10.2 \mid) \\
1\end{array}$ & 0.008 \\
\hline Perceived difficulty to engage in ASM & $\begin{array}{l}\text { High } \\
\text { Low }\end{array}$ & $\begin{array}{l}122(62.9 \%) \\
72(37.1 \%)\end{array}$ & $\begin{array}{l}14(7.2 \%) \\
180(92.8 \%\end{array}$ & $\begin{array}{l}21.78(I 1.76-40.37) \\
\text { । }\end{array}$ & $\begin{array}{l}10.13(4.3 \mid-23.84) \\
\mid\end{array}$ & 0.000 \\
\hline Intervention coherence & $\begin{array}{l}\text { Good } \\
\text { Poor }\end{array}$ & $\begin{array}{l}56(28.9 \%) \\
138(7 \mid .1 \%)\end{array}$ & $\begin{array}{l}|4|(72.7 \%) \\
53(27.3 \%)\end{array}$ & $\begin{array}{l}\text { I } \\
6.55(4.21-10.21)\end{array}$ & $3.15(1.54-6.43)$ & 0.002 \\
\hline Presence of opportunistic cost & $\begin{array}{l}\text { High } \\
\text { Low }\end{array}$ & $\begin{array}{l}146(75.3 \%) \\
48(24.7 \%)\end{array}$ & $\begin{array}{l}59(30.4) \\
135(69.6 \%)\end{array}$ & $\begin{array}{l}6.96(4.45-10.88) \\
1\end{array}$ & $\begin{array}{l}3.34(1.64-6.83) \\
I\end{array}$ & 0.001 \\
\hline Self-efficacy & $\begin{array}{l}\text { High } \\
\text { Low }\end{array}$ & $\begin{array}{l}75(38.9 \%) \\
119(61.3 \%)\end{array}$ & $\begin{array}{l}179(92.3 \%) \\
15(7.7 \%)\end{array}$ & $\begin{array}{l}\text { I } \\
\text { I8.94(I0.38-34.53) }\end{array}$ & $\begin{array}{l}\text { I } \\
7.44(3.16-17.46)\end{array}$ & 0.000 \\
\hline $\begin{array}{l}\text { Presence of competing family } \\
\text { activities }\end{array}$ & $\begin{array}{l}\text { Yes } \\
\text { No }\end{array}$ & $\begin{array}{l}69(35.6 \%) \\
125(64.3 \%)\end{array}$ & $\begin{array}{l}116(59.8 \%) \\
78(40.2 \%)\end{array}$ & $\begin{array}{l}\text { I } \\
2.69(1.78-4.06)\end{array}$ & I $4.39(2.05-9.44)$ & 0.000 \\
\hline Presence of stigma & $\begin{array}{l}\text { Yes } \\
\text { No }\end{array}$ & $\begin{array}{l}116(59.8 \%) \\
78(40.2 \%)\end{array}$ & $\begin{array}{l}88(45.4 \%) \\
106(54.6 \%)\end{array}$ & $\begin{array}{l}1.79(1.19-2.68) \\
1\end{array}$ & $\begin{array}{l}2.85(1.39-5.81) \\
I\end{array}$ & 0.004 \\
\hline
\end{tabular}


nearly three times more likely to be non-utilizers of ASM as compared to clients who had been on ART for more than 5 years. This finding explains that, the longer the client has been receiving the care services, the more it will help them to know more about the benefit of involvement in the progressively emerging HIV/AIDS care initiatives through experience.

Clients who had poor understanding (intervention coherence) of ASM were about four times more likely to be non-utilizers of ASM than those with good understanding. Though equipping the clients with pertinent information about the model is up to the health care providers, sometimes clients may not be counseled as necessary. This supports the study in Malawi, in which lack of stability status check resulted in enrollment of both stable and nonstable clients almost equally to the model. ${ }^{22}$ Clients had poor coherence of how ASM utilization works to improve service quality provided to them by offloading the burden on healthcare providers and allotting ample time for thorough clinical evaluation which is critical to quality care. This may lead them to perceive the model as of no more importance than a mere extension of appointment date. This may in turn affect their motive to be included in the model.

HIV patients who had high perceived difficulties of engagement in ASM were about twelve times more likely to be non-utilizers of the model as compared to clients who had low perceived difficulties. This finding has to do with the fact that, long duration between subsequent visits may impose cognitive difficulties in remembering the schedule at each visit. This may necessitate a device mechanism to remind those clients with particular difficulties so that the clients are alerted ahead of appointment dates.

HIV patients with low self-efficacy to overcome difficulties associated with ASM utilization were about eight times more likely to be non-utilizers of the model compared to those who had shown high self-efficacy. This finding has to do with the fact that, those who have cognitive and objective ability to overcome challenges, which they may think could hinder them from utilizing the service (perceived difficulties) are better at accepting and utilizing the service. For example, those who commit to using a message alarm, prepare their own safe drug storage place and so on.

Clients perceiving presence of high opportunistic cost were about three and a half times more likely to be nonutilizers of the model compared to those with low opportunistic cost. This has to do with the fact that longer duration of staying away from visiting ART clinic may induce additional cost by with-holding ancillary service they might have obtained had they visited the facility. This assumption may arise from misunderstanding and $\mathrm{sub}=$ optimal counseling, ie, that being on the model does not mean one could not visit the facility in=between his/ her appointment dates if the need arises.

Clients who need frequent checkups were about three times more likely to be non-utilizers of the model than those who did not. This finding supports the study finding in Nigeria which shows the disadvantages of long=spaced visits; like loss of ancillary service, reduced opportunity of interaction with provider and increased risk of disclosure in community-based approach of differentiated service delivery model. ${ }^{33}$ This may be because most chronic diseases like hypertension, diabetes-mellitus and bronchial asthma have short appointment plans such as 1-2 months. So it is inevitable for the client to visit a health facility in a period much shorter than six months. This fact may necessitate one to get his/her HIV related service at the same time.

Clients who reported any form of stigma were about three times more likely to be non-utilizers of ASM than those who did not. This supports the finding from the study conducted at 6 pilot Hospital in Ethiopia which showed the major reason cited for refusal to enroll in ASM was: fear of inadvertent disclosure (due to having a large volume of medication). ${ }^{11}$ Non-disclosure of one's HIV status may be strongly related to presence of HIV related stigma and discrimination in the community. The image with which HIV/AIDS had figured out for prevention purpose during the era when anti-retroviral drugs had not yet been introduced, and when treatment and cares were not well established in our country makes it difficult to remove stigma related to HIV/AIDS in the community.

A study conducted in Kenya showed, women who did not disclose their HIV status had lower maternity and PMTCT service utilization. Among HIV positive women, the effect of disclosure to anyone, on ARV drug use and facility birth, remains large and significant. ${ }^{33,34}$ Therefore, provision of ample drugs for six month period may expose clients to inadvertent exposure and associated stigma. This may be the reason why non-utilization of ASM was higher among clients who reported presence of HIV-related stigma. This finding supports a study from India, which showed accessing treatment, quality of life and survival were affected by stigma among women living with HIV infection. ${ }^{13}$ 
Finally, clients who reported history of having no competing family activity (eg caring for children, work) were about three times more likely to be non-utilizers of ASM as compared to those who had competing family activities. This shows poor effort to change client preferences as enrollment in ASM has more implications to improve collective care outcome than mere personal choice.

This study was conducted during a time where not much was known about ASM non-utilization risk factors in Ethiopia. Therefore, the information can help to understand the situation at this time as there are more care centers and numbers of patients enrolled in chronic care are increasing. Follow up studies need to be conducted to understand the full spectrum of the intervention and its role in improving continuum of service and retention in care. The limitation of the current study was that it focused only on the quantitative data and there is absence of qualitative part.

Important information about factors associated with ASM non-utilization for planners and decision-makers was provided in this study. It can support them to improve program implementation and HIV/AIDS care service efficiency by increasing engagement of stable ART clients in appointment spacing model in Ethiopia.

Based on the findings and conclusion from this study, differentiated service delivery program should focus on provision of effective evidence based counseling especially regarding behavioral part associated with chronic care and importance of ASM utilization. Adherence supporters (AS) and case managers (ACM) should encourage and support those underserved clients through sharing their own and/or others' best experience as necessary.

Equipping clients with necessary information: service providers should provide information for the clients on how ASM benefits them in the long run by reducing waiting time, cost of service, and improving quality of care etc. Providing sufficient information, clearing clients' confusion and fear concerning the intervention are very important to create a positive energy in clients, which in turn influences their perception, affective feelings and preferences.

Adoption of additional model of DSD: one of the major factors associated with non-utilization of ASM was fear regarding drug safety and HIV related stigma (which is associated with fear of inadvertent disclosure due to provision of large volume of drugs for long duration). Therefore, $\mathrm{FMoH}$ and Regional health bureau should consider adoption of additional option of facility-based model. For example, the fast track drug refill model, which allows three-month drug refill at pharmacy and sixmonth clinical evaluation, may best solve the problem associated with the previously-mentioned factors.

More research on subject matter: academicians and researchers should further conduct qualitative study and assess the impact of ASM utilization on improving client retention in ART care. Finally, a strategy to optimize ASM utilization should focus on intensive client screening and counseling, and training of providers.

\section{Conclusion}

From the finding, majority of factors affecting ASM nonutilization were behavioral and community related, which can be addressed by health education both at client and community level. Additionally, by training service providers to address factors connected to service provision, it is possible to conclude that there is poor needs-based screening and counseling of ART clients on the rationale of using ASM. This may imply that providers themselves poorly internalize how it could help by offloading health care workers' burden and improve health service efficiency where limited resources are prevalent.

\section{Disclosure}

The authors report no conflicts of interest for this work.

\section{References}

1. UNAIDS. UNAIDS DATA reference 2019. Available from: https:// www.google.com/search?client $=$ opera\&q=UNAIDS+DATA+reference $+2019 \&$ sourceid $=$ opera\&ie $=U T F-8 \& o e=U T F-8$. Accessed December 31, 2020.

2. HIV epidemic estimates 2017-2021. Ethiopia. Available from: www. hapco.gov.et. Accessed December 31, 2020.

3. Kebede W (MD/MPH). Participant Manual for the Clinical Mentoring Training Course. Federal ministry of health Ethiopia; 2018.

4. Yigeremu A, Seblewongel AA. Guideline for HIV Care/ART Clinical Mentoring. FDRE Federal Ministry of Health: Ethiopia. March, 2007:1-49.

5. Pham M, Romero L, Parnell B, Anderson D, Crowe S, Luchters S. Feasibility of antiretroviral treatment monitoring in the era of decentralized HIV care: a systematic review. Aids res there. Biomed Cent. 2017;14(1):3.

6. Bekolo C, Diallo A, Philips M, et al. Six-monthly appointment spacing for clinical visits as a model for retention in HIV care, in Conakry-guinea: a cohort study. BMC Infect Dis. 2017;17(1):766. doi:10.1186/s12879-017-2826-6

7. The united Republic of Tanzania. Ministry of Health, Community Development, Gender, Elderly and Child, HIV Service Delivery Models. HIV Service Delivery Models Mapping. HIV Service Delivery Strategies in Tanzania. 2016.

8. Bekolo C, Diallo A, Philips M, et al. Six-monthly appointment spacing for clinical visits as a model for retention in hiv care in conakry-guinea: a cohort study. BMC Infect Dis. 2017;1-10. doi:10.1186/s12879-016-2122-x 
9. Agency C, Ababa A. Federal democratic republic of ethiopia demographic and health survey. 2018.

10. PEPFAR. Ethiopians and Americans in Partinership to Fight HIV/ Aids:differentiated Care in Ethiopia the Way Forward. March, 2017.

11. The International AIDS Society (IAS). Differentiated Care for HIV: A Decision Framework for ART Delivery. 2016.

12. Melaku AZ, Amdino W, Abebe A, Rabkin M, Hartsough K, Fayorsey R. Implementation of appointment spacing model of differentiated care in Ethiopia-successes and challenges. Ethiopia ASM AIDS. 2018.

13. Short W, Vissandjée B. Review article research article living with hiv in india: looking up from women a place of stigma, identifying nexus sites for change. Divers Equal Health Care. 2017;14:159-166.

14. Network of networks of HIV positives in Ethiopia (nep+). The people living with HIV stigma index country. July, 2011. Available from: www.nepplus.org. Accessed December 31, 2020.

15. Prust ML, Banda CK, Nyirenda R, et al. Multi-month prescriptions, fast track refills, and community art groups: results of process evaluation in Malawi on using differentiated models of care to achieve national HIV treatment goals. $J$ Int AIDS Soc. 2017;20 (suppl4):21650. doi:10.7448/IAS.20.5.21650

16. Babigumira J, Castelnuovo B, Stergachis A, et al. Cost effectiveness of a pharmacy-only refill program in a large urban HIV/AIDS clinic in Uganda. PLoS One. 2011;6(3):e18193. doi:10.1371/journal.pone.0018193

17. Obua $\mathrm{C}$, Kayiwa $\mathrm{J}$, Waako $\mathrm{P}$, et al. Improving adherence to antiretroviral treatment in Uganda with a low-resource facility-based intervention. Glob Health Action. 2014;7. doi:10.3402/gha.v7.24198

18. Mcguire M, Pedrono P, Mukhua B, Huckabee M, Heinzelmann A, Szumilin E. Optimizing patient monitoring after the first year of art: three years of implementing 6-monthly clinical appointments in rural malawi. 2011.

19. Bemelmans M, Baert S, Goemaere E, et al. Community-supported models of care for people on hiv treatment in sub-saharan africa. Trop Med Int Health. 2014;19(8):968-977. doi:10.1111/tmi.12332

20. Cawley C, Nicholas S, Szumilin E, et al. Six-monthly appointments as a strategy for stable antiretroviral therapy patients: evidence of its effectiveness from seven years of experience in a medecins sans frontieres supported programme in chiradzulu district, malawi aids. 21st international aids conference; July 18-22; 2016; Durban.

21. Mody A, Roy M, Sikombe K, et al. Improved retention with six month clinic return intervals for stable hiv-infected patients in zambia . Clin Infect Dis. 2017;66(2):237-243.

22. Mesic A, Fontaine J, Aye T, et al. Implications of differentiated care for successful art scale-up in concentrated hiv epidemic in yangon, myanmar. J Int AIDS Soc. 2017;20(suppl 4):21644. doi:10.7448/ IAS.20.5.21644
23. Clinton health foundation. Assessing Implementation of Models of Differentiated Care for HIV Service Delivery in Malawi; Evidence from a Process Evaluation. 2016.

24. Aidala AA, Lee G, Abramson DM, Messeri P, Siegler A. Housing need, housing assistance, and connection to HIV medical care in new York city. AIDS Behav. 2007;11(2):101-115.

25. Ayalew M. Mortality and its predictors among hiv infected patients taking antiretroviral treatment in ethiopia. AIDS Res Treat. 2017;2017.

26. WHO. Web_annex_4_WHO_Workforce_Statistics_data for 193 Countries. Vols. 2008-11. 2010.

27. Tanzania Ministry of Health. HIV Service Delivery Models. Mapping HIV Service Delivery Strategies in Tanzania; 2016. Available from: https://differentiatedservicedelivery.org/Portals/0/adam/ Content/nKMF99s69UqVMa9DJQp96A/File/SDM_Tanzania Mapping\%20Report_04pril2017_FINAL.pdf.

28. Alamo S, Wagner G, Ouma J, et al. Strategies for optimizing clinic efficiency in a community-based antiretroviral treatment programme in uganda. AIDS Behav. 2013;17(1):274-283. doi:10.1007/s10461012-0199-9

29. Nsanzimana S, Remera E, Muhayimpundu R, et al. Phased implementation of spaced clinic visits for stable hiv-positive patients in rwanda to support treat all. J Int AIDS Soc. 2017;20(suppl 4):21635. doi:10.7448/IAS.20.5.21635

30. Neely BC. Unstable housing among persons living with HIV/AIDS (PLWHA): a review of the literature and cost comparison of organizations that may provide shelter and related services. 2016 .

31. Kolawole GO 1, Gilbert HN 2, Dadem NY 1, et al. Patient experiences of decentralized HIV treatment and care in Plateau State, North Central Nigeria: a Qualitative Study. AIDS Res Treat. 2017;2017:1-10. doi:10.1155/2017/2838059

32. Wanless R, Kim M, Golin R, et al. Multi-month prescription of antiretroviral therapy and its feasibility: experiences from the baylor international pediatric aids initiative (bipai) in six southern african countries. 9th international aids society conference on hiv science; July 22-27; 2017; paris.

33. Mandeep S, Martin C, Jill J. Acceptability of healthcare interventions: an overview of reviews and development of a theoretical framework. BMC Health Serv Res. 2017;17:88. doi:10.1186/s12913-017-2031-8

34. Spangler S, Onono M, Bukusi E, Cohen C, Turan J. Hiv-positive status disclosure and use of essential pmtct and maternal health services in rural kenya. $J$ Acquir Immune Defic Syndr. 2014;67:235-242. doi:10.1097/QAI.0000000000000376
HIV/AIDS - Research and Palliative Care

\section{Publish your work in this journal}

HIV/AIDS - Research and Palliative Care is an international, peerreviewed open-access journal focusing on advances in research in HIV, its clinical progression and management options including antiviral treatment, palliative care and public healthcare policies to control viral spread. The manuscript management system is completely online and includes a very quick and fair peer-review system, which is all easy to use. Visit http://www.dovepress.com/testimonials.php to read real quotes from published authors. 